TJVR 2021; 5 (1): 17-23

Turkish Journal of Veterinary Research

http://www.dergipark.gov.tr/tjvr

e-ISSN: 2602-3695

\title{
Immunohistochemical investigation of lipid peroxidation in renal coccidiosis of geese
}

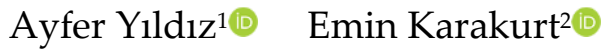 \\ ${ }^{1}$ Department of Pathology, Institute Health Sciences, Kafkas University, Kars, Turkey \\ ${ }^{2}$ Department of Pathology, Faculty of Veterinary Medicine, Kafkas University, Kars, Turkey
}

\begin{abstract}
Objective: In this study, we aimed to evaluate the oxidative damage caused by lipid peroxidation due to renal coccidiosis by histopathological and immunohistochemical methods.
\end{abstract}

Material-Method: The material of this study was made up of tissue samples taken from 139 geese whose average age was 10 weeks, who were brought to our department dead between 2013-2020. Tissue samples taken were fixed in $10 \%$ buffered formaldehyde solution. $5 \mu \mathrm{m}$-thick sections were taken from the paraffin blocks prepared after routine tissue follow-up procedures. Hematoxylin \& Eosin staining was applied to the sections in order to detect histopathological changes. Sections were examined and photographed under a light microscope.

Results: Various clinical signs such as fever, respiratory distress, weakness, anorexia, tremors, inability to get up from the ground, balance disorders, rotational movement, diarrhea, wheezing were detected in geese. In systemic necropsies of geese, large and small white nodular structures were detected in the kidney. In histopathological examinations, coccidiosis agents (E. truncata) were found in the tubular epithelium of the kidney. Necrosis and mononuclear cell infiltration were observed in the tubules due to the presence of E. truncata. In addition, edema and hyperemia in the lungs, multifocal necrosis in the liver, cell infiltration in the portal spaces and enteritis were other important histopathological findings. In one case, aspergillosis was detected together with renal coccidiosis. We observed that MDA expression was more severe in oocyst stages, which is the mature form of the parasite, compared to other parasitic life stages.

Conclusion: Based on the results obtained from this study, it was revealed that renal coccidiosis in geese caused lipid peroxidation / oxidative damage through the increase in MDA expression.

Keywords: Histopathology, Goose, Lipid peroxidation, MDA, Renal coccidiosis

\section{INTRODUCTION}

Coccidiosis is a serious protozoan disease that causes hemorrhagic diarrhea, depression, weakening, wing drooping, sensitivity to other diseases and loss of body weight, as well as deaths, especially in young animals, caused by various Eimeria species (Sarı and Çakmak, 2008; Liu et al., 2018; Fortuoso et al., 2019). Coccidiosis, which is common in many parts of the world, causes serious problems in many animal species such as cattle, sheep, goats, dogs, cats, pigs and rabbits, especially in poultry (Dumanlı and Aktaş, 2015; Song et al., 2017). Avian coccidiosis has a high morbidity and mortality rate and the economic loss it causes is more than 3 billion dolllars annually (Galli et al., 2019; Griss et al., 2019). Parasites continue their development in the interstitial canal or kidneys according to the species differences and do not need 
any intermediate hosts during their development (Dai et al., 2005; Dalloul and Lillehoj, 2006). The disease is more severe in young animals than adults, and the risk of infection is higher, especially in 3-12 week old goslings. The acute form of renal coccidiosis has a high mortality rate of $80 \%$ (Hilbert, 1951; Dumanlı and Aktaş 2015). This parasite causes deaths in young animals, and the elderly animals that survive the disease become susceptible, causing them to play a role in carrying the disease as a carrier (Arslan et al., 2002; Dumanlı and Aktaş 2015; McDougald, 2020). A total of 17 Eimeria species have been isolated in domestic and wild geese. 7 species have been seen in domestic geese, it has been reported that only one species is Tyzzeria and the others belong to the Eimeria lineage (Karaer and Çiçek, 2013; Song et al., 2017). E. anseris, E.cotlani, E. noces, E. parvula, E.stigmosa, E. truncata and Tyzzeria anseris are coccidiosis species isolated in geese (Hanson et al., 1957; Arslan et al., 2002). It has been reported that intestinal coccidiosis is caused by E. anseris and renal coccidiosis is generally caused by E.truncata (Montgomery, 1978; Arslan et al., 2002). Endogenous development of $E$. truncata occurs in the tubular epithelial cells of geese kidneys (Entzeroth et al., 1981). Cases of renal coccidiosis are diagnosed by the presence of oocysts in the kidneys and cloaca near the urethra (McDougald 2020).

Free radicals are highly active chemical products that occur during metabolism in the body. The most important free radicals in biological systems are radicals formed from oxygen and these are called Reactive Oxygen Species (ROS) (Atmaca and Aksoy, 2009). Reactive oxygen species initiate lipid peroxidation by causing oxidation in polyunsaturated fatty acids (PUFA) found in biological membranes (Özcan et al., 2015). By cleavage of polyunsaturated fatty acids containing three or more double bonds, one of the most important indicators of lipid peroxidation is Malondialdehyde (MDA), a three-carbon dialdehyde (Tabakoğlu and Durgut, 2013).

In this study, we aimed to evaluate the oxidative damage caused by lipid peroxidation due to renal coccidiosis in geese by histopathological and immunohistochemical methods.

\section{MATERIALS and METHODS}

\section{Animals}

The material of this study was made up of tissue samples taken from 139 geese whose average age was 10 weeks, who were brought to our department dead between 2013-2020. Information on age, clinical symptoms, parasitic forms and the severity of MDA immune positive expressions for all animals are given in Table 1.

\section{Ethical Approval}

The ethics committee report of this study was obtained from Kafkas University Animal Experimentals Local Ethics Committee (Authorization number: KAU-HADYEK-2020/166).

\section{Histopathological Investigations}

After systemic necropsy of geese, tissue samples were fixed in $10 \%$ buffered formalin solution. After routine procedures paraffin blocks were cut to $5 \mu \mathrm{m}$ thickness and Hematoxylin \& Eosin (H\&E) staining was applied to the sections in order to detect histopathological changes. In order to reveal the presence of Aspergillus fungi, Periodic acid-Schiff (PAS) staining was applied to the sections as suggested by Facepath company. Sections were examined and photographed under a light microscope.

\section{Immunohistochemical Investigations}

Avidin-Biotin Peroxidase method was used as immunohistochemical method. For immunohistochemical staining, the sections of $4 \mu \mathrm{m}$ in thickness taken to poly-L-lysine coated slides were deparaffinized and rehydrated in graded alcohols. In order to prevent endogenous peroxidase activity, the sections were treated with $3 \%$ hydrogen peroxide solution in Phosphate Buffered Saline (PBS) for 15 minutes. For antigen retrieval, the sections were boiled in Citrat Buffer Solution ( $\mathrm{pH} \mathrm{6)}$ for $25 \mathrm{~min}$ in the microwave oven (at 800 watt). In order to prevent nonspecific staining, the sections were incubated for $10 \mathrm{~min}$ with non-immune serum (Thermo Scientific Histostain-Plus IHC Kit, HRP, broad spectrum, REF: TP-125-HL) at room temperature. Diluted antibodies (MDA: Abcam, ab6463, Dilution Rate: 1/250) were incubated for overnight $\left(+4{ }^{\circ} \mathrm{C}\right.$ in refrigerator). The sections were washed 3 times in PBS solution for 5 minutes, and the biotinylated secondary antibody (Thermo Scientific, HistostainPlus IHC Kit, HRP, broad spectrum, REF: TP-125HL) was applied to them at room temperature for 10 minutes. After washing in PBS (3-5 min), all sections were incubated with peroxidase-bound Streptavidin (Thermo Scientific, Histostain-Plus IHC Kit, HRP, broad spectrum, REF: TP-125-HL) for 10 minutes at room temperature. A solution of 3.3diaminobenzidine tetra hydrochloride (DAB) 
(Thermo Scientific, REF: TA-125-HD) was used as a chromogen for 15 minutes. The sections were treated with Mayer's Hematoxylin for 30 second and washed in running water for $5 \mathrm{~min}$, dehydrated in graded alcohols, cleared in xylene and coated with entellan. Primary antibodies were omitted from the negative control sections and were treated with diluted normal serum. The slides prepared after the covering were examined under a light microscope (Olympus Bx53) and photographed via the Cell^ ${ }^{\wedge}$ program (Olympus Soft Imaging Solutions $\mathrm{GmbH}, 3,4)$. Analyzes of the images were done with Image J Program. Results were evaluated as negative $(-)$, mild $(+)$, moderate $(++)$ and severe $(+++)$.

Table 1. Age, clinical symptoms, microscopic results and severity of MDA expressions of all animals

\begin{tabular}{|c|c|c|c|c|}
\hline Case No & $\begin{array}{c}\begin{array}{c}\text { Age } \\
\text { (week) }\end{array} \\
\end{array}$ & Clinical Symptoms & Parasitic form & $\begin{array}{c}\text { MDA } \\
\text { expressions }\end{array}$ \\
\hline 1 & 9 & Fever, anorexia & Oocyst & +++ \\
\hline 2 & 9 & Anorexia, depression & Oocyst & ++ \\
\hline 3 & 6 & Weakness, anorexia & Macro/micro gamet & + \\
\hline 4 & 12 & Balance disorders, diarrhea & Oocyst & +++ \\
\hline 5 & 12 & Rotational movement around its axis, diarrhea & Oocyst & +++ \\
\hline 6 & 10 & Diarrhea, emaciation & Oocyst & ++ \\
\hline 7 & 9 & Diarrhea & Oocyst & +++ \\
\hline 8 & 8 & Tremor & Micro/macro gamet & + \\
\hline 9 & 10 & Inability to get up from the ground & Micro/macro gamet & ++ \\
\hline 10 & 12 & Diarrhea, balance disorders & Oocyst & +++ \\
\hline 11 & 12 & Diarrhea, balance disorders & Oocyst & +++ \\
\hline 12 & 10 & Rotational movement around its axis & Oocyst & ++ \\
\hline 13 & 10 & Rotational movement around its axis & Oocyst & +++ \\
\hline 14 & 10 & Rotational movement around its axis & Oocyst & +++ \\
\hline 15 & 10 & Inability to get up from the ground & Oocyst & +++ \\
\hline 16 & 8 & Respiratory distress, wheezing & Micro/macro gamet & ++ \\
\hline 17 & 9 & Diarrhea, balance disorders & Micro/macro gamet & + \\
\hline
\end{tabular}

\section{RESULTS}

\section{Clinical Symptoms}

Various clinical symptoms such as fever, respiratory distress, weakness, anorexia, emaciation, tremor, inability to get up from the ground, balance disorders, rotational movement around its axis, diarrhea, wheezing.

\section{Macroscopical Results}

We observed large and small yellowish-white nodular structures in the kidneys of 17 (12.23\%) of 139 geese examined macroscopically (Figure 1).

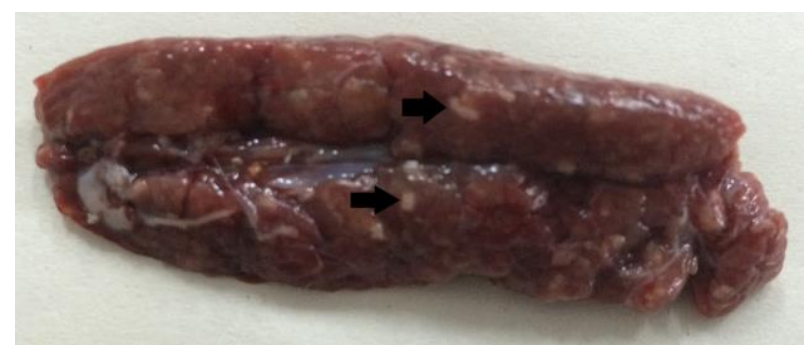

Figure 1 Yellowish-white nodular structures (arrows) in the kidney. 

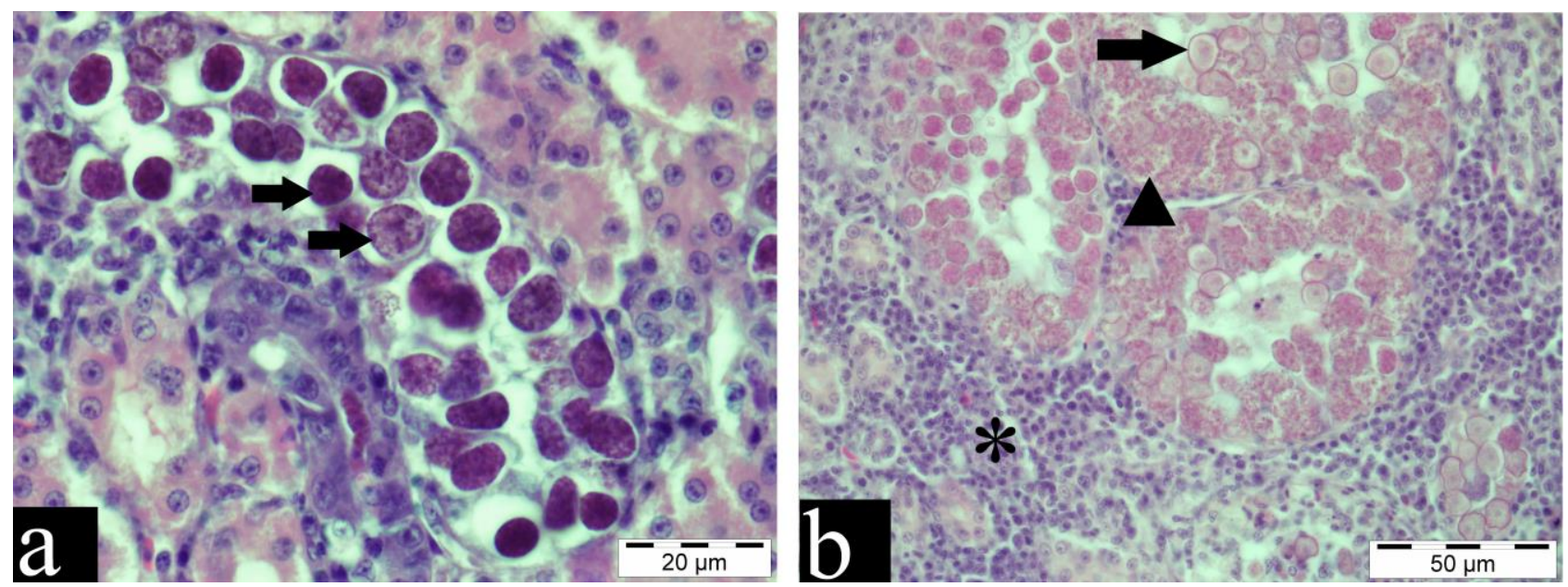

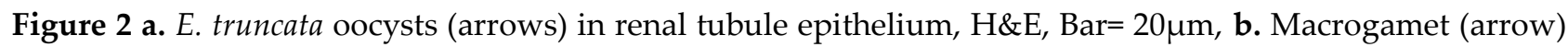
and microgamet (arrowhead) stages of E. truncata in renal tubule epithelium and nephritis (star), H\&E, Bar = $50 \mu \mathrm{m}$
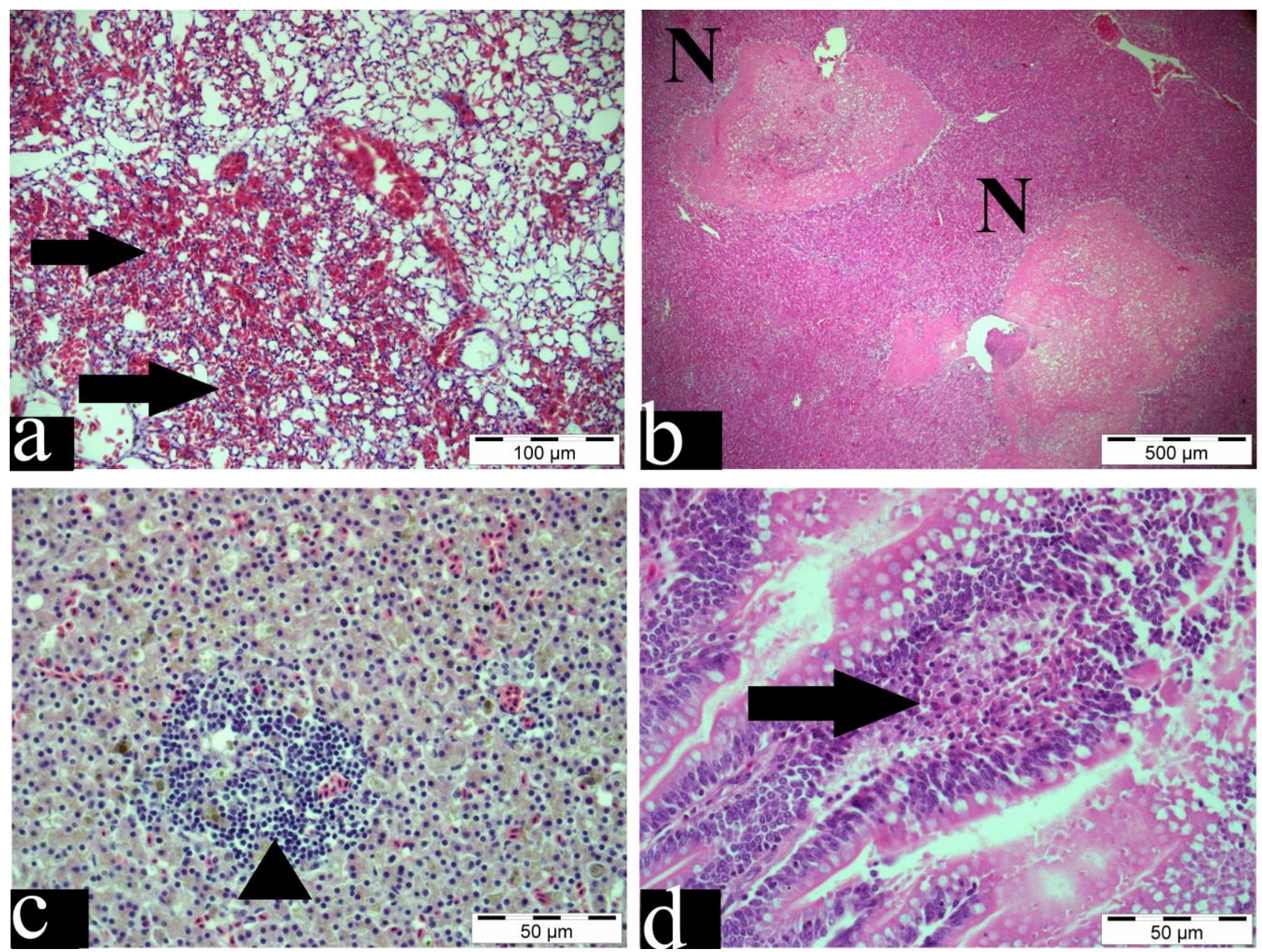

Figure 3 a. Lung, hyperemic areas (arrows) in lungs, H\&E, Bar $=100 \mu \mathrm{m}, \mathrm{b}$. Liver, necrotic areas (N), H\&E, Bar $=100 \mu \mathrm{m}$, c. Liver, mononuclear cell infiltration (arrowhead), H\&E, Bar $=50 \mu \mathrm{m}, \mathrm{d}$. Intestine, diphteroid necrotic enteritis, $\mathrm{H} \& \mathrm{E}, \mathrm{Bar}=50 \mu \mathrm{m}$ 

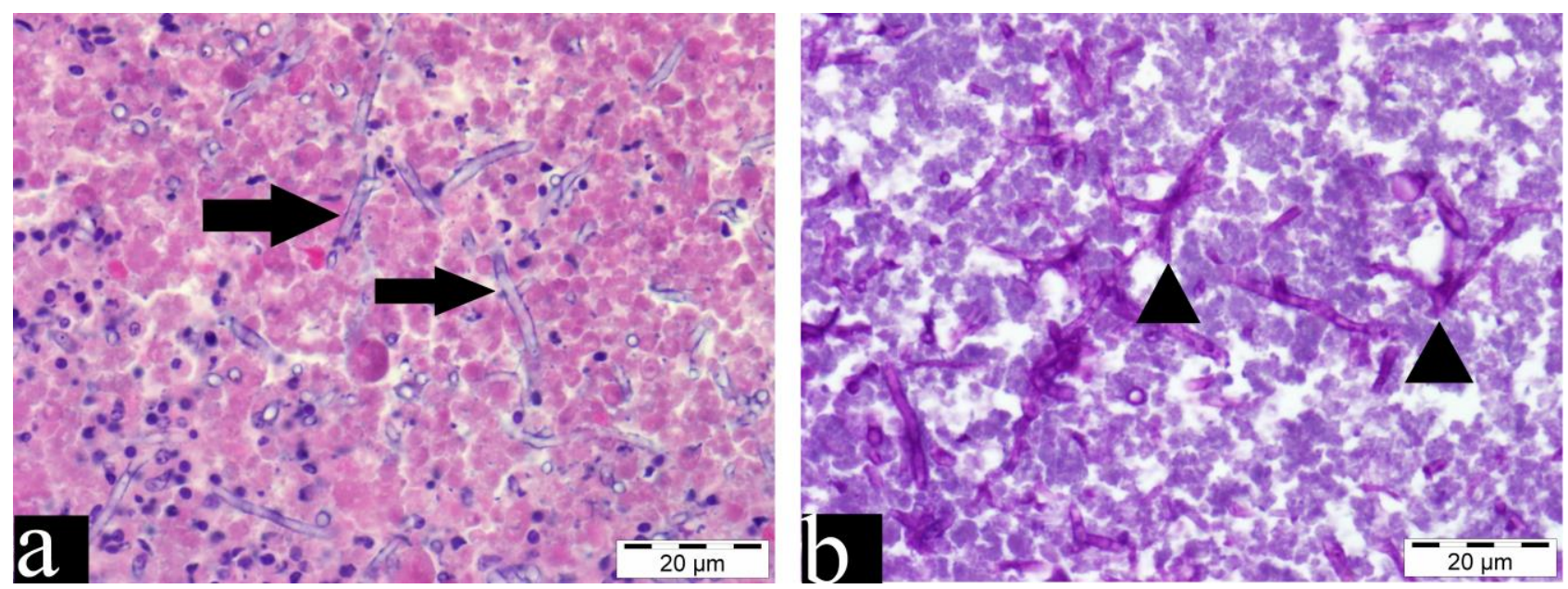

Figure 4 a. Lung, hyphae (arrows), H\&E, Bar = $20 \mu \mathrm{m}$, b. Lung, hyphae (arrowheads), PAS staining, Bar = 20 $\mu \mathrm{m}$
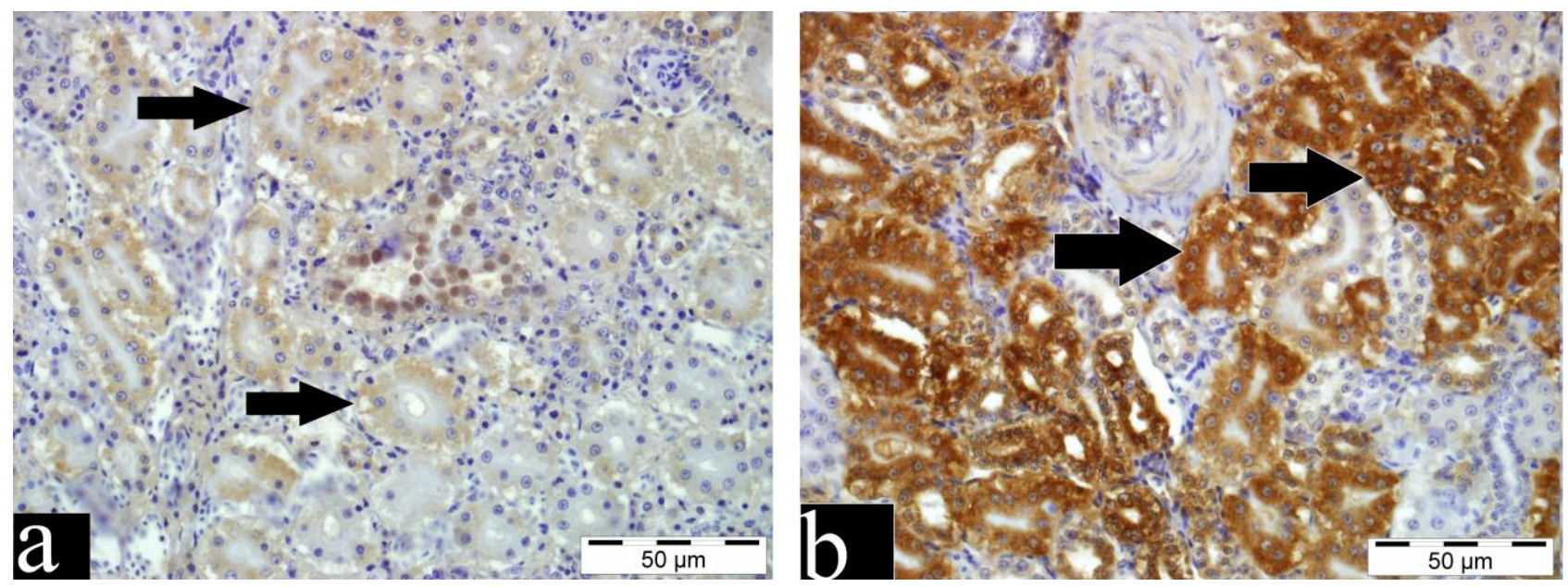

Figure 5 a. Kidney, oocyst form, MDA expressions in degenerated and necrotic tubular epithelium (arrows), IHC, Bar=50 $\mu \mathrm{m}, \mathbf{b}$. Kidney, oocyst form, severe intracytoplasmic MDA expressions in degenerated and necrotic tubular epithelium around the inflammatory area (arrows), IHC, Bar=50 $\mu \mathrm{m}$

\section{Microscopical Results}

We identified different life forms of coccidiosis factors in renal tubular epithelium (Figure $2 \mathrm{a}-\mathrm{b}$ ). In addition to these, nonpurulent nephritis, necrosis in the renal tubular epithelium, edema and hyperemia in the lungs, necrosis in liver and hepatitis, and diphteroid necrotic enteritis in the intestines were among the other important histopathological findings (Figure 3 a-d). We detected pulmonary aspergillosis (PAS positive) in only one goose (Figure 4 a-b).

\section{Immunohistochemical Results}

We detected MDA immune positive expression especially in degenerated and necrotic tubular epithelium. We observed that MDA expression was more severe in oocyst stages, which is the mature form of the parasite, compared to other life stages (macrogamet and microgamet) (Figure $5 \mathrm{a}-\mathrm{b}$ ).

\section{DISCUSSION}

While goose breeding is an important sector after chicken and turkey breeding in many parts of the world, it is not yet at the desired size in our country. In our country, goose breeding is mostly carried out in the Eastern Anatolia Region (Kars, Ardahan, Muş, Ağrı and Van) at the family level and the interest in goose breeding is increasing every year. The presence of geese grown in Turkey, North East Region, especially Ardahan and Kars provinces constitute approximately half of the total assets of the country geese (Demir et al., 2013; Otlu, 2016). One of the most important problems encountered in goose breeding is the fight against infectious 
diseases and protection (Sar1 and Saatc1, 2020). One of the most important of these infectious diseases is coccidiosis infection caused by parasites related to Eimeria lineage, which causes significant losses in goose breeding (Liu et al., 2018; Wang et al., 2020).

In this study, in accordance with the literature data (Entzeroth et al., 1981; Tuggle and Crites, 1984; Dumanlı and Aktaş, 2015) the mean age range of the geese with renal coccidiosis was 10 weeks. Various clinical symptoms such as diarrhea, depression, anorexia, and emaciation have been reported in previous studies (Arslan et al., 2002; Dai et al., 2005; Song et al., 2017; Liu et al., 2018; Wang et al., 2020) in geese with renal coccidiosis. In our study, in addition to these clinical symptoms, we identified different clinical symptoms such as respiratory distress, tremor, inability to get up, balance disorders, rotational movement around their axis, and wheezing. We thought that this diversity observed in clinical symptoms may be related to the fact that parasitic factors weaken the immune system and predispose to the formation of other diseases (Liu et al., 2018; Fortuoso et al., 2019).

Similar to the literature (Hilbert, 1951; Montgomery, 1978; Gajadhar et al., 1982; Tuggle and Crites, 1984) we also observed large and small white nodular structures in the kidneys in systemic necropsies of geese. Parallel to previous studies, in the histopathological examination of the kidneys, we detected different parasitic forms of E.truncata in the renal tubular epithelium (Klimeš, 1963; Entzeroth et al., 1981; Gajadhar et al., 1982; Gajadhar et al., 1986), severe degeneration and necrosis (Oksanen, 1994; Arslan et al., 2002) and inflammatory infiltration in which the majority of mononuclear cells (Montgomery, 1978; Tuggle and Crites, 1984) were formed. Findings such as hepatitis, enteritis, and pulmonary aspergillosis, which we thought to be caused by avian coccidiosis increasing predisposition to other disease factors, were among the other important histopathological changes we found (Liu et al., 2018; Wang et al., 2020).

Oxidative stress is an imbalance between antioxidant and oxidant status (Tabakoğlu and Durgut, 2013). This imbalance is related to the overproduction, or slowing down of the removal of these free radicals, such as ROS (Özcan et al., 2015). ROS overproduction causes to damage of nucleic acids, lipids and proteins. Oxidative stress plays a serious role in the initiation and progression of many infectious diseases such as coccidiosis (Griss et al., 2019). It has been reported that coccidiosis in animals causes an increase in ROS and reactive nitrogen species (RNS), causes changes in antioxidant enzyme activities and a decrease in the concentrations of antioxidants (Khatlab et al., 2019). Fortuoso et al., (2019) found that serum ROS levels and lipid peroxidation increased in broiler chickens experimentally infected with Eimeria. In another study, an increase in intestinal ROS production with lipid peroxidation has been reported in chicks experimentally infected with Eimeria species (Galli et al., 2019). In addition, an increase in MDA levels, which is an important marker of lipid peroxidation, was detected in the experimentally induced Eimeria infection in broiler chickens (Muraina et al. 2020). According to literature (Fortuoso et al., 2019; Galli et al., 2019; Griss et al., 2019; Khatlab et al., 2019; Muraina et al. 2020) we found that the expression of MDA in renal coccidiosis of geese increased significantly in different life forms of the parasite. We interpreted this increase in MDA expression as lipid peroxidation-based oxidative stress may play an important role in the pathogenesis of the disease.

\section{CONCLUSION}

According to clinical, macroscopic and microscopic findings, the presence of renal coccidiosis was $12.23 \%(17 / 139)$ in 139 dead geese samples brought to our department in the last 8 years in Kars, which is an important goose breeding region. We concluded that coccidiosis plays an important role in goose deaths. In the literature searches, we did not find any studies in which lipid peroxidation was evaluated immunohistochemically by means of MDA expression in renal coccidiosis of geese. In this respect, we thought that the results obtained from our study would contribute to the literature on the pathogenesis of renal coccidiosis of geese.

\section{ACKNOWLEDGMENTS}

This study was presented orally and printed as summary text in congress book in $10^{\text {th }}$ National \& $1^{\text {st }}$ Veterinary Pathology Congress, 27-31 October 2020, Burdur/Turkey

Conflict of Interests: The authors declared that there is no conflict of interests.

Financial Disclosure: The authors declared that this study has received no financial support.

Author's Contributions: EK and AY designed the study. AY collected the goose samples. He did immunohistochemical and H\&E staining, source scanning, and photography. EK performed microscopic evaluations of the staining. 


\section{REFERENCES}

Arslan MÖ, Gıck Y, Özcan K. The frequency of Eimeriidae species in the domestic geese in Kars province of Turkey. Acta Protozool. 2002; 41:353-357.

Atmaca E, Aksoy A. Oksidatif DNA hasarı ve kromatografik yöntemlerle tespit edilmesi. YYU Vet Fak Derg. 2009; 20:7983.

Dai Y, Liu X, Liu M, Tao J. The life cycle and pathogenicity of coccicium Eimeria nocens (Kotlán, 1933) in domestic goslings. J Parasitol. 2005; 91:1122-1126.

Dalloul RA, Lillehoj HS. Poultry coccidiosis: recent advancements in control measures and vaccine development. Expert Rev Vaccines. 2006; 5:143-163.

Demir P, Kırmızıbayrak T, Yazıcı K. Kaz yetiştiriciliğinin sosyoekonomik önemi. Ankara Üniv Vet Fak Derg. 2013; 60:129124.

Dumanlı Z, Aktaş M. Eimeriidae (Coccidiosis in Poultry). In: Dumanlı N, Karaer KZ, eds. Veterinary Protozoology. $2^{\text {nd }} \mathrm{ed}$. Ankara: Medisan Publishing House; 2015. p.105-124.

Entzeroth R, Scholtyseck E, Sezen IY. Fine structural study of Eimeria truncata from the domestic goose (Anser anser dom.). Z Parasitenkd. 1981; 66:1-7.

Fortuoso BF, Baldissera MD, Souza CF, et al. Impairment of the phosphotransfer network and performance in broiler chickens experimentally infected by Eimeria spp.: The role of the oxidative stress. Parasitol Int. 2019; 70:16-22.

Galli GM, Baldissera MD, Griss LG, et al. Intestinal injury caused by Eimeria spp. impairs the phosphotransfer network and gain weight in experimentally infected chicken chicks. Parasitol Res. 2019; 118:1573-1579.

Gajadhar AA, Cawthorn RJ, Rainnie DJ. Experimental studies on the life cycle of a renal coccidium of lesser snow geese (Anser c. caerulescens). Can J Zool. 1982; 60:2085-2092.

Gajadhar AA, Stockdale PH. Ultrastructural studies of microgametogenesis and macrogametogenesis of Eimeria truncata of the lesser snow goose. J Protozool. 1986; 33:345351.

Griss LG, Galli GM, Fracasso M, et al. Oxidative stress linked to changes of cholinesterase and adenosine deaminase activities in experimentally infected chicken chicks with Eimeria spp. Parasitol Int. 2019; 71:11-17.

Hanson HC, Levine ND, Ivens V. Coccidia (Protoza: Eimeriidae) of North American wild geese and swans. Can J Zool. 1957; 35:715-733.

Hilbert KF. Renal coccidiosis in a goose on Long Island. Cornell Vet. 1951; 41:54-55.

Karaer Z, Çiçek H. Coccidiosis infections in poultry. In: Özcel MA, İnci A, Köroğlu E, Karaer Z, Eren H, Yukarı BA, Dumanlı Z, Aydın L, Yıldırım A, eds. Parasitic Diseases in Veterinary Medicine Volume. $1^{\text {st }}$ ed. Izmir: Meta Printing Services; 2013. p.539-550.
Khatlab AS, Del Vesco AP, de Oliveira Neto AR, Fernandes RPM, Gasparino E. Dietary supplementation with free methionine or methionine dipeptide mitigates intestinal oxidative stress induced by Eimeria spp. challenge in broiler chickens. J Animal Sci Biotechnol. 2019;10:58.

Klimeš B. Coccidia of the domestic goose (Anser anser dom.). Zoonoses Public Health. 1963; 10:427-448.

Liu J, Liu L, Li L, et al. Protective immunity induced by Eimeria common antigen 14-3-3 against Eimeria tenella, Eimeria acervulina and Eimeria maxima. BMC Vet Res. 2018; 14:337.

McDougald LR. Protozoal infections. In: Swayne DE, Boulianne M, Logue CM, McDougald LR, Nair V, Suarez DL, eds. Diseases of Poultry. 14 $4^{\text {th }}$ ed. New Jersey: Wiley-Blackwell; 2020. p.1193-1217.

Montgomery RD, Novilla MN, Shillinger RB. Renal coccidiosis caused by Eimeria gaviae n. sp. in a common loon (Gavia immer). Avian Dis. 1978; 22:809-814.

Muraina IA, Gotep JG, Tanko JT, et al. Anticoccidial effects of Khaya senegalensis aqueous stem bark extract on broiler chickens experimentally infected with Eimeria species. Trop Anim Health Prod. 2020; 52:1249-1255.

Oksanen A. Mortality associated with renal coccidiosis in juvenile wild greylag geese (Anser anser anser). J Wildl Dis. 1994; 30:554-556.

Otlu S. Infectious disease in geese. Turkiye Klinikleri J Reprod Artif Insemin-Special Topics. 2016; 2:56-65.

Özcan O, Erdal H, Çakırca G, Yönden Z. Oxidative stress and its impact on intracellular lipids, proteins and DNA. J Clin Exp Invest. 2015; 6:331-336.

Sarı B, Çakmak A. Etlik piliçlerde coccidiosis'den korunmada anticoccidial katkılı yem uygulamalarının etkisi. Kocatepe Vet J. 2008; 1:1-10.

Sar1 M, Saatc1 M. Biosecurity procedures with the all aspects in goose breeding. TURJAF. 2020; 8:35-41.

Song $\mathrm{H}$, Liu D, Xu J, et al. The endogenous development and pathogenicity of Eimeria anseris (Kotlan, 1932) in domestic goslings. Parasitol Res. 2017; 116:177-183.

Tabakoğlu E, Durgut R. Veteriner hekimlikte oksidatif stres ve bazı önemli hastalıklarda oksidatif stresin etkileri. AVKAE Derg. 2013; 3:69-75.

Tuggle BN, Crites JL. Renal coccidiosis in interior Canada geese, Branta canadensis interior Todd, of the Mississippi Valley population. J Wildl Dis. 1984; 20:272-278.

Wang $\mathrm{XH}, \mathrm{Yu} \mathrm{HL}$, Zou WB, et al. Study of the relationship between polymorphisms in the IL-8 gene promoter region and coccidiosis resistance index in Jinghai yellow chickens. Genes. 2020; 11:476. 